\title{
Formulation and Characterization of pH based Stimuli Sensitive based Hydrogels for the Treatment of Ocular Infection
}

\author{
Nagalakshmi Sethuraman ${ }^{1 *}$, Anbarasan Balu1, Ramesh Selvaraj', Thanka Johnson², Shanmuganathan Seetharaman ${ }^{1}$ \\ 'Faculty of Pharmacy, Department of Pharmaceutics, Sri Ramachandra Medical College and Reserach Institute, Porur, Chennai, Tamil Nadu, INDIA. \\ 2Department of Pathology, Sri Ramachandra Medical College and Research Institute, Porur, Chennai, Tamil Nadu, INDIA.
}

\begin{abstract}
Objective: The goal of the study was to formulate and characterized the $\mathrm{pH}$ stimuli sensitive based hydrogels for the effective treatment of infected eye. Method: Simple method of preparation was adapted. Result: The optimized formulations was undergone the characterization studies such as XRD spectrum analysis, FTIR analysis, Gelling capacity, Drug content, Determination of viscosity, surface tension of the optimized formulations, DSC analysis, in-vitro release study of the optimized formulations, Ex-vivo release studies of best formulation and stability studies. The pre-formulation studies confirm the drug and polymer are compatible with each other. The F5 formulation showed the maximum percentage of drug release around $97.08 \%$ in drug release study. The ex-vivo study showed $95.57 \%$ of drug release for the period of 7 hours. Further, the optimized formulations were most stable in room temperature when compared to higher temperature. Conclusion: The prepared formulations of $\mathrm{pH}$ based hydrogels were optimized; developed formulations are used as treatment for ocular drug
\end{abstract}

delivery system with increase in precorneal time, reduced frequency of the dosage and to achieve the patient compliance.

Key words: Hydrogels, Viscosity, Ex-vivo study, Stimuli, Sensitive, Gelling Capacity.

Key Messages: To prepare the $\mathrm{pH}$ based in-situ gel the transition of sol to gel plays vital role in the smart drug delivery system.

Correspondence

S. Nagalakshmi, Department of Pharmaceutics, Faculty of Pharmacy, Sri Ramachandra Medical College and Reserach Institute, Porur, Chennai-600116, Tamil Nadu, INDIA.

Phone: 9176468060

Email: nagalakshmimpharm@gmail.com

DOI: 10.5530/jyp.2018.10.9

\section{INTRODUCTION}

In the human body, the organ eye plays a most vital role. Through which can see all over the world. The parts of the eye are cornea, lens, sclera, optic nerves, pupil and etc. The most important struggle through ocular route contains non- productive absorption, tear fluid drainage, make of lacrimation, turnover of tears and drug impermeability to cornea. , $^{1,2,3}$ Solutions, suspensions, ointments and etc. they are the different conventional dosage forms shows a little constriction in increase of pre-corneal elimination, high unpredictability in efficiency, distorted vision and also weaken their bioavailability.

Ofloxacin is an antibiotic which comes under the class fluoroquinolone i.e. second generation. This antibiotic is active against both gram-positive and gram- negative bacteria. The mode of action of the antibiotic is functioning by inhibiting DNA gyrase, a type II topoisomerase and topoisomerase IV, which is an enzyme necessary to separate replicated DNA, thereby inhibiting bacterial cell division. The side effects of these type antibiotics are insomnia, diarrhoea, nausea, headache and vomiting. The overdose of these antibiotics will be resulted in hepatic toxicity, tendon/articular toxicity, central nervous system toxicity (CNS) and cardio vascular toxicity. The drug has most high penetration rate into ocular tissues due to its nearer neutral $\mathrm{pH}$ which is $\mathrm{pH} 6.4$ and it is more tolerable. ${ }^{4,5}$

The polymers used in the preparation are poly acrylic acid (PAA) which always trends to cross link with allyl ether of propylene, allyl ether of sucrose or allyl ether penta erythritol. The polymer while in water solution loses their proton and gains the negative charge. This makes the polymer poly electrolytes, which has the tendency to absorb water and retain, and also the polymer swells to its maximum times from its original volume.
Hypromellose in an aqueous solution, unlike methylcellulose, exhibits a thermal gelation property. The conventional dosage forms have some major disadvantages facing by the researchers are short residence time, loss of drug through naso-lachrymal drainage, impermeability of corneal epithelium, frequent instillation, poor bioavailability and more absorption in systemic circulation. Wide-ranging research has been approved in scheming of polymeric drug delivery systems. ${ }^{6}$ The enlargement of in situ gel systems has inward bound significant awareness over the past few years.

Overall, the advantages of the in-situ preparations are to increase the pre-corneal residence time, minimizes the interference of blinking, permeability of corneal epithelium, less frequency of administration, in order to increase the bioavailability and less adsorption in systemic circulation and also improved the patient compliance and their comfort.?

\section{MATERIALS AND METHODS}

The drug Ofloxacin, polymers like Carbopol (1,250,000M.W.), HPMC (low \& high Viscous) \& Benzalkonium chloride were purchased from Sigma Aldrich chemicals - Bangalore. $\beta$-cyclodextrin, sodium chloride was purchased from Fischer chemicals Ltd-Chennai. Sodium bicarbonate, calcium chloride, citric acid was purchased from Fischer chemicals Ltd-Chennai. All other solvents used were of analytical grade.

\section{Method of preparation: (Formulation of in-situ gel)}

The different formulations of the in-situ gel were prepared by dissolving the polymers Carbopol $(1,250,000)$ and cellulose derivatives (HPMC low viscous $\&$ high viscous) in citro- phosphate buffer $\mathrm{pH} 6$ and was allowed to hydrate. To this $\beta$-cyclodextrin, sodium chloride and Benzalkonium 
chloride were added. Drug solution (ofloxacin) was prepared and transferred to the above solution, until identical solution was obtained. Final volume was adjusted by using citro- phosphate buffer of $\mathrm{pH} 6$ and the composition of various prepared formulations was shown in the Table 2. They were then kept in autoclave for sterilization process at $121^{\circ} \mathrm{C}, 15 \mathrm{psi}$ for $20 \mathrm{~min}$ and the samples were evaluated for further studies. ${ }^{8}$

\section{RESULTS}

\section{XRD Spectrum of the Drug and Excipient}

$\mathrm{X}$-ray diffration spectrum of the drug samples and the polymer samples are done by XRD diffractometer analysis. The diffractograms was recorded under the following situation as Volt $-45 \mathrm{kV}$, Current $-30 \mathrm{~mA}$ and further maintained in room conditions. Those data were measured using scattering angle $(2 \theta)$ ranged $10-90^{\circ}$. Moreover, drug, polymers and the prepared formulation were compared with each other in order to verify whether it is crystalline or in amorphous state.

\section{Fourier Transforms Infra Red Spectrum (FTIR) studies}

To recognize the functional groups, present in the pure drug, polymers and formulation prepared were compared. Any interactions between the drug and polymer molecules were identified. IR spectrums of samples were measured from 4000 to $400 \mathrm{~cm}^{-1}$ by using instrument Perkin Elmer FTIR spectrophotometer. Spectrum for Drugs, polymers and drug formulation were taken and compared. ${ }^{9}$

\section{Gelling time}

Determination of in-vitro gelling capacity was done by visual/observation method. Coloured solutions were prepared by adding $1 \%$ Amaranth dye solution in water and mixed with prepared formulations. $5 \mathrm{ml}$ of gelation solution is taken in the fresh glass test tube which contains STF fluid 7.4 and it was maintained in room temperature conditions. $20 \mu \mathrm{l}$ $50 \mu \mathrm{l}$ of coloured dye formulation was added to the gelation solution drop by drop by using pipette then it gets immediately converted into gel like structure (transition of sol-gel). The gelling capacity of solution was evaluated on the basis of stiffness gelation (Figure 3). Coloured dye was added in the formulation in order to visualize the appearance of in-situ gel formation. The gelation time and time period plays vital role in formation of gel and remains as such, which easily predicts the evaluation parameters of gelation capacity. ${ }^{10,11}$

\section{Determination of Rheological studies of the formulations (F1-F5)}

The viscosities of the formulations (F1-F5) were measured by the Brookfield Viscometer DV2T model. The in-situ formulations were taken in the sampling tube and analyzed in the room temperature $\left(25^{\circ} \mathrm{C}\right)$. The spindle 18 was connected to the viscometer in such a position and the samples were measured at $15 \mathrm{rpm}$ for duration of 5 minutes. Finally, obtained values were measured in units as Centipoises (M.W.). ${ }^{12,13}$

\section{Drug content}

$1 \mathrm{ml}$ of formulations was taken and diluted with $0.1 \mathrm{~N} \mathrm{HCl}$ solution to $100 \mathrm{ml}$ standard flask. Further, $5 \mathrm{ml}$ of stock solution was taken and diluted to $25 \mathrm{ml}$ standard flask. Then the sample was subjected to UV spectrophotometric analysis. The drug content of the drug (ofloxacin) was measured at $294 \mathrm{~nm}$ respectively.

\section{Determination of Surface tension by Drop weight Method}

Stalagmometer was rinsed with water, acetone and dried. The stalagmometer was filled with water up to the mark A by keeping in vertical position. Specific gravity bottle were taken washed with water and acetone. It was dried well and weight of the empty specific gravity bottle was taken. Then 20 drops of the water were collected in specific gravity bottle and weighed. Finally weight of a single drop of water is calculated. Similar procedure is adapted for each formulation (F1-F5).

\section{Differential Scanning Calorimeter (DSC)}

In order to recognize any possible change in the physical state of drug, polymer (carbopol 1,250,000 M.W., HPMC (both low \& high) and combination, DSC was performed on drug with polymer combination, pure drug and polymers used in a thermal analysis system (DSC-60, Shimadzu). The sample $\left(5 \mathrm{mg}\right.$ ) was heated at a constant rate of $10^{\circ} \mathrm{C} / \mathrm{min}$ in an aluminium pan under a nitrogen atmosphere. Similarly empty pan was used as a reference.

\section{In-vitro release studies}

The release studies of prepared formulations were carried out by using Franz Diffusion Cell (FDC) method. Donor compartment contains the formulations F1 - F5 and STF fluid in the receptor compartment. The experiment was done at room temperature withdrawing $3 \mathrm{ml}$ of sample for every $1 \mathrm{hr}$ for a period of $8 \mathrm{~h}$ and was replaced with refresh medium after every withdrawal. The sample was analyzed spectrophotometrically at $294 \mathrm{~nm}$; the cumulative \% release was calculated for the prepared formulations F1 - F5 as shown in the Figure 3.14,15

\section{Pharmacokinetics}

Evaluation of in-vitro release kinetics (Theoretical calculation from \% Cumulative drug release). To study the release kinetics, data obtained from in-vitro release were fitted with various kinetic models such as Zero order reaction, first order reaction, Korsmeyer Peppas reaction, Higuchis Kinetics model and Hixson Crowell erosion equation methods.

\begin{tabular}{|c|c|c|}
\hline Figure & Wave number $\left(\mathrm{cm}^{-1}\right)$ & Vibrations \\
\hline 2(a) & $\begin{array}{c}3042,2787,1709,1620,1520,1454,1287,198,1137,1048,1009,954,8 \\
76,798 \text { and } 704 .\end{array}$ & $\begin{array}{c}\mathrm{N}-\mathrm{H}, \mathrm{C}=\mathrm{H}, \mathrm{C}=\mathrm{O} \text { and } \mathrm{C}=\mathrm{N} \text { are stretching, } \mathrm{N}-\mathrm{H}, \mathrm{C}-\mathrm{H}, \mathrm{C}-\mathrm{N}, \mathrm{C}-\mathrm{H} \& \mathrm{C}-\mathrm{C} \text { bending. } \\
\mathrm{N}-\mathrm{H} \text { rocking. }\end{array}$ \\
\hline 2(b) & $2936,2361,1703,1451,1415,801$ and 618. & $\begin{array}{l}\mathrm{C}-\mathrm{H} \text { and } \mathrm{C}-\mathrm{H}=\mathrm{O} \text { are stretching. } \mathrm{C}-\mathrm{C}, \mathrm{C}-\mathrm{H}, \mathrm{O}-\mathrm{H} \text { are bending. } \mathrm{C}-\mathrm{C} \text { is stretching. } \\
\text { C- } \mathrm{H} \text { rocking. }\end{array}$ \\
\hline $2(\mathrm{c})$ & $3407,2927,2386,1710,1619,1521,1399,1050,949$ and 774 & $\begin{aligned} \mathrm{O}-\mathrm{H}, \mathrm{C}-\mathrm{H}, \mathrm{C}=\mathrm{O}-\mathrm{H}, \mathrm{C}=\mathrm{O} \text { and } \mathrm{C}=\mathrm{C} \text { are stretching. } \mathrm{N}-\mathrm{H} \text { is bending. } \mathrm{C}=\mathrm{O} \text { and } \\
\\
\text { C- } \mathrm{C} \text { stretching. } \mathrm{C}-\mathrm{H} \text { rocking. }\end{aligned}$ \\
\hline 2(d) & $3434,2925,2362,1709,1619,1399,1242,1197,1050,961$ and 708 & $\begin{array}{c}\mathrm{O}-\mathrm{H}, \mathrm{C}=\mathrm{O}-\mathrm{H}, \mathrm{C}=\mathrm{O} \text { and } \mathrm{C}=\mathrm{C} \text { are stretching. } \mathrm{N}-\mathrm{H} \text { and } \mathrm{O}-\mathrm{H} \text { are bending. } \mathrm{C}-\mathrm{O} \\
\text { and } \mathrm{C}-\mathrm{C} \text { stretching. } \mathrm{N}-\mathrm{H} \text { rocking. }\end{array}$ \\
\hline $2(\mathrm{e})$ & $3429,2914,1709,1620,1401,1197,105,949$ and 707 & $\begin{array}{l}\mathrm{O}-\mathrm{H}, \mathrm{C}=\mathrm{O}-\mathrm{H}, \mathrm{C}=\mathrm{O} \text { and } \mathrm{C}=\mathrm{C} \text { are stretching. } \mathrm{N}-\mathrm{H} \text { and } \mathrm{O}-\mathrm{H} \text { are bending. } \mathrm{C}-\mathrm{O} \\
\text { and } \mathrm{C}-\mathrm{C} \text { stretching. } \mathrm{N}-\mathrm{H} \text { and } \mathrm{C}-\mathrm{H} \text { are rocking. }\end{array}$ \\
\hline
\end{tabular}

Moreover, the functional groups present in the drug, polymer and HPMC (low \& high) were showed no interaction between the molecules of them 
The drug release obeys zero-order release and case II transport if the $\mathrm{n}$ value is 1 . If the values of $\mathrm{n}$ higher than 1 , then the drug release mechanism is regarded as super case II transport. The release kinetics of pharmaceutical dosage forms for the formulated preparations can be able to indentified by the release mechanism, which is not known already and also which obeys more than one type of release mechanism based on the above model analyse only. The $n$ value could be obtained from slope of the plot of log cumulative \% of drug released Vs log time.

These optimized formulation F5 obeys the Zero order and followed by the koresmeyer- Peppas equation were the regression coefficient $\left(\mathrm{R}^{2}\right)$ value showed maximum as shown in the Table 3 . The $n$ value is slightly greater than the standard value 0.5 so, it follows non-Fickian model (Anomalous transport).

\section{Ex-vivo Studies}

The goat cornea was purchased from slaughter house and washed with water for several minutes. They were soaked in the STF fluid for few minutes. The goat cornea was preferred as the membrane for the Franz diffusion cell. Goat corneas were kept in between donor and receptor compartment. The formulations F5 was taken for the ex-vivo studies based on the release study showed maximum \% cumulative drug release and it was taken in donor compartment. The studies were carried out for the period of 8 hours by withdrawing the sample and replacing $3 \mathrm{ml}$ of STF fluid from the receptor compartment. Then the sample was by UV visible spectrophotometer at $294 \mathrm{~nm}$ and the graph was plotted with \% cumulative drug release vs. time.

\section{Stability studies}

The stability studies were carried out on the developed formulations as per the ICH guidelines. Formulations were stored in tightly closed amber coloured glass vials sealed with aluminium foil at room temperature $25^{\circ} \mathrm{C} \pm 2{ }^{\circ} \mathrm{C}$ and $40^{\circ} \mathrm{C} \pm 2{ }^{\circ} \mathrm{C}, 75 \% \mathrm{RH}$ for a period of $0-6$ months. Finally the samples from stability chamber are taken and re-dispersed in D. I. Water by vortex for 3-5 min. The prepared in-situ gel was subjected for drug content measurements by UV visible spectrophotometer at $294 \mathrm{~nm}$ $(n=3)$ where all the formulations were done in triplicate as shown in the Table 4.

\section{Anti-bacterial activity}

\section{Preparation of inoculums by Agar well diffusion method}

Stock cultures were maintained at $4^{\circ} \mathrm{C}$ on slant of nutrient agar. Active cultures for experiments were prepared by transferring a loop full of cells from the stock cultures to test tubes of nutrient broth for bacteria that were incubated at $24 \mathrm{~h}$ at $37^{\circ} \mathrm{C}$. The Assay was performed by agar disc diffusion method.

\section{Procedure}

Antibacterial activity of sample was determined by well diffusion method on Muller Hinton agar (MHA) medium. The Muller Hinton Agar medium was weighed as $3.8 \mathrm{gms}$ and dissolved in $100 \mathrm{ml}$ of distilled water and add $1 \mathrm{gm}$ of agar. Then the medium is kept for sterilization. After sterilization the media was poured in to sterile petriplates and were allowed to solidify for $1 \mathrm{hr}$. After the medium was solidified, the inoculums were spread on the solid plates with sterile swab moistened with the bacterial suspension. Wells were made $10 \mu \mathrm{l}, 20 \mu \mathrm{l}, 30 \mu \mathrm{l}$ sample, negative control $20 \mu \mathrm{l}$ water and positive control $20 \mu \mathrm{l}(10 \mu \mathrm{g})$ ofloxacin was added to respective wells on MHA plates. These plates were incubated for $24 \mathrm{~h}$ at $37^{\circ} \mathrm{C}$. Then the microbial growth was determined by measuring the diameter of zone of inhibition. ${ }^{16,17}$ No. of Microorganism: 2 (Escherichia coli, Bacillus subtilis)

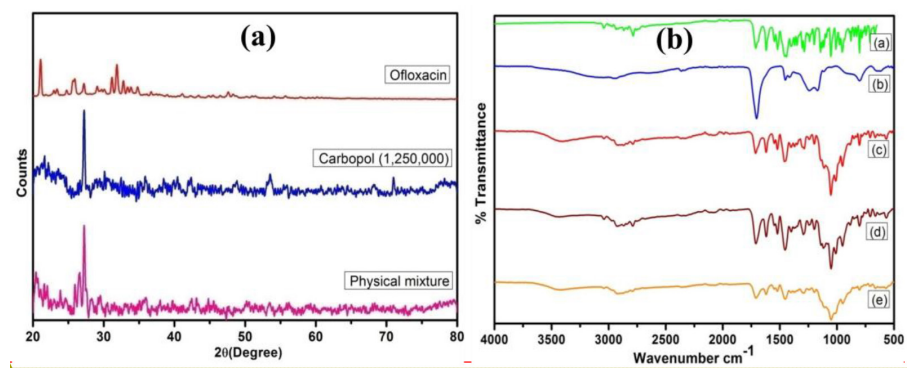

Figure 1(a): XRD spectrum showed the peak positions $(2 \theta)$ of the drug, polymer and the mixture of the drug with polymers.

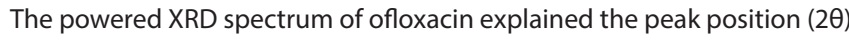
at $20.77^{\circ}, 22.10^{\circ}, 24.05^{\circ}, 26.24^{\circ}, 26.97^{\circ}, 27.68^{\circ}$ and $29.75^{\circ}$. The polymer Carbopol (1,250,000M.W.) showed the peak position $(2 \theta)$ at $21.74^{\circ}$ and $27.21^{\circ}$. Then the mixture of drug and polymer showed the sharp peak in the figure 1 and the peak position $(2 \theta)$ at $27.37^{\circ}$ whereas the remaining peaks of the drug gets merged in the polymer as shown in the figure 1. So, they exhibited amorphous state when compared to the pure drug.

Figure 1(b): FTIR spectrum (a) showed the spectrum of Ofloxacin, (b) showed the spectrum of Carbopol 1,250,000. (c) Showed the spectrum of Ofloxacin + HPMC low + Carbopol 1,250,000 (d) showed the spectrum of Ofloxacin + HPMC high + Carbopol 1,250,000 and (e) showed the spectrum of Ofloxacin + HPMC high \& low + Carbopol 1,250,000

From the FTIR graph, the interpretation were plotted in the Table 1 as shown

\section{DISCUSSION}

The motive of the preparation of the in-situ gels were to increase pre-corneal residence time, avoid passage of lachrymal fluid through GIT, reduced dosage forms and to achieve better patient compliance. The $\mathrm{pH}$ based in-situ gels were obtained by transition of sol into gel. The method was used to prepare as simple procedure. The optimization of formulation indicated that the combination of Carbopol $(1,250,000)$, HPMC (both Low \& high Viscosity) showed maximum period of gelling capacity when compared to the other formulations. From the above results the XRD signals (Figure 1(a)) indicated the formulation is amorphous in condition when compared with pure individual drug and the polymer. Further, the FTIR spectrum indicates that the drug polymer doesn't interact with each other. No interaction between the molecules of drug and polymer confirms that the drug and polymer molecule binds with each other by physical bond or Vander Waal's force. So, that the bond can easily broken and bind with any other molecule and the spectrum were predicted in the Figure 1(b). From the Figure 2 the gelling time showed the occurrence of gel formation which remained for about 8-10 hours. Further, the viscosity of the prepared formulations at $15 \mathrm{rpm}$ of speed and kept for 5 minutes duration as set time. Out of which formulation F5 showed maximum viscous (before formation of gel -74 Cps, after formation of gel-90.89Cps) compared to other formulations. The drug content of the different formulations (F1-F5) was measured by using UV visible spectrophotometer at $294 \mathrm{~nm}$ and the formulations F4 showed the maximum drug content of $96.89 \%$ whereas F1 showed 95.77\%, F2 showed $92.81 \%$, F3 showed $94.15 \%$ and F5 showed $93.74 \%$ were slightly less compared to the formulations F4. The surface tension of the prepared gel formulations can be measured by drop weight method or by drop count method. Here we have used drop weight method to calculate surface tension for one drop of the formulation. The surface tension of the formulations F1-F5 was measured by using stalagmometer and drop weight method was chosen for the study. The results don't show much difference between the formulations. The Formulation F4 showed 46.32 dynes/cm, F3 showed 43.55 dynes/cm, Formulation F5 showed 
Table 2: indicated the optimization of formulations (F1-F5) along with the $\mathrm{pH}$, clarity and gelling time.

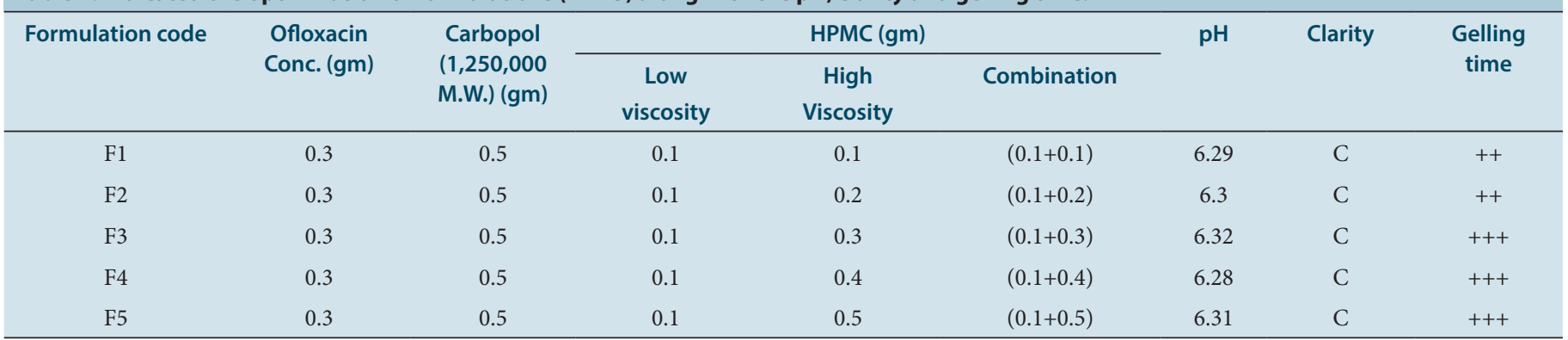

\begin{tabular}{|c|c|c|c|c|c|}
\hline \multirow[t]{2}{*}{ FORMULATION CODE } & \multirow{2}{*}{$\begin{array}{l}\text { DRUG CONTENT } \\
\text { (\%) at } 0 \text { month }\end{array}$} & \multicolumn{2}{|c|}{$\begin{array}{l}\text { DRUG CONTENT } \\
\text { (\%) at } 3 \text { month }\end{array}$} & \multicolumn{2}{|c|}{$\begin{array}{l}\text { DRUG CONTENT } \\
(\%) \text { at } 6 \text { month }\end{array}$} \\
\hline & & $25^{\circ} \mathrm{C}$ & $40^{\circ} \mathrm{C} \pm 2^{\circ} \mathrm{C} 75 \% \mathrm{RH}$ & $25^{\circ} \mathrm{C}$ & $40^{\circ} \mathrm{C} \pm 2^{\circ} \mathrm{C} 75 \% \mathrm{RH}$ \\
\hline $\mathrm{F} 1$ & $95.77 \pm 0.6$ & $95.24 \pm 0.47$ & $94.04 \pm 0.52$ & $94.89 \pm 0.18$ & $92.17 \pm 0.21$ \\
\hline $\mathrm{F} 2$ & $92.81 \pm 0.81$ & $92.73 \pm 0.97$ & $91.51 \pm 1.07$ & $92.03 \pm 1.45$ & $91.44 \pm 0.57$ \\
\hline F3 & $94.15 \pm 1.84$ & $93.91 \pm 0.68$ & $93.14 \pm 0.17$ & $93.22 \pm 0.64$ & $92.84 \pm 0.58$ \\
\hline F4 & $96.89 \pm 0.94$ & $96.48 \pm 0.27$ & $96.27 \pm 0.22$ & $96.37 \pm 1.08$ & $95.52 \pm 1.64$ \\
\hline F5 & $93.74 \pm 0.32$ & $93.59 \pm 0.48$ & $93.11 \pm 0.57$ & $93.39 \pm 0.69$ & $92.10 \pm 0.85$ \\
\hline
\end{tabular}

\begin{tabular}{|c|c|c|c|c|c|}
\hline \multirow[t]{2}{*}{ Formulation (F5) } & \multicolumn{5}{|c|}{ Zone of Inhibition (Diameter in $\mathrm{mm}$ ) } \\
\hline & $\begin{array}{c}1000 \mu \mathrm{g} \\
(\mathrm{A}-10 \mu \mathrm{l})\end{array}$ & $\begin{array}{c}500 \mu \mathrm{g} \\
(\mathrm{B}-20 \mu \mathrm{l})\end{array}$ & $\begin{array}{c}200 \mu \mathrm{g} \\
(\mathrm{C}-30 \mu \mathrm{l})\end{array}$ & $\begin{array}{c}\text { (D - Negative } \\
\text { Control) }\end{array}$ & (E-Standard) \\
\hline Escherichia coli & 31 & 30 & 27 & - & 20 \\
\hline Bacillus subtilis & 28 & 28 & 28 & - & 20 \\
\hline
\end{tabular}
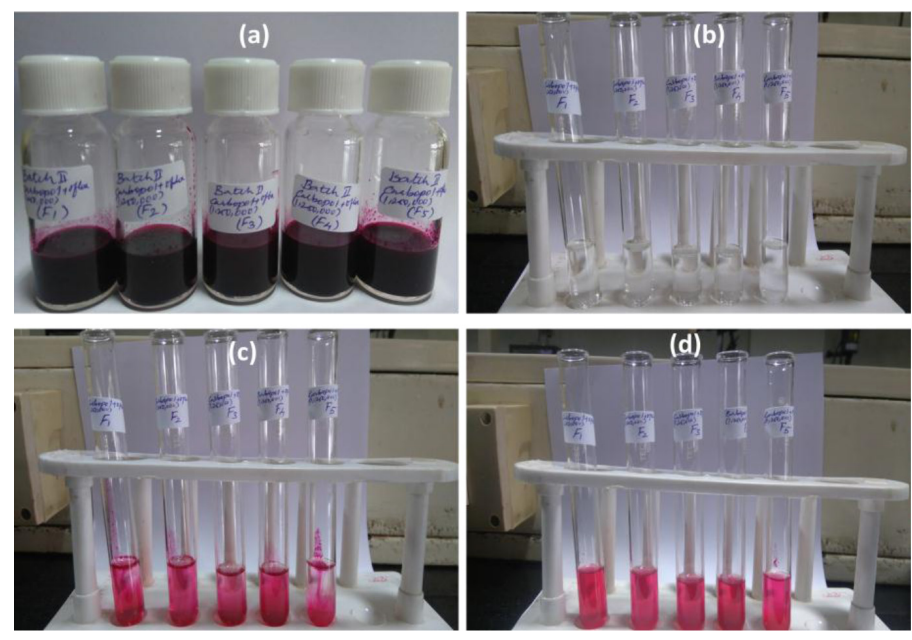

Figure 2: Showed the prepared preparations of F1-F5

(a) Showed the prepared formulations are added with amaranth dye (coloured solution).

(b) Showed the Simulated Tear fluid (STF) fluid 7.4 in the test tube.

(c) Addition of 20-50 $\mu$ l formulation to the simulated Tear Fluid (STF) indicates the formation of gel (Transition of sol to gel).

(d) Showed the occurrence of gel formation this remained for about 8-10 hours. Note: Gelling time indicates the,

(+) Gelation occurred after a few minutes and gel dissolved rapidly,

$(++)$ Gelation immediate remains up to $6-8$ hours and

$(+++)$ Gelation immediate remains more than $8-10$ hours.
39.77 dynes/cm, F1 showed 39.02 dynes/cm and F2 showed 38.76 dynes $/ \mathrm{cm}$. From the obtained thermo gram of pure drug ofloxacin at $275^{\circ} \mathrm{C}$ and predicted the endothermic reaction. Meanwhile the peak at $278^{\circ} \mathrm{C}$ showed the sudden rise and indicated the exothermic reaction while the polymer carbopol 1,250,000 M.W. were also showed endothermic reaction, where the onset of peak starts at $40^{\circ} \mathrm{C}$ and the offset of peak ends in $125^{\circ} \mathrm{C}$. Area of the curve was calculated. Similarly, the polymer HPMC (low \& high) showed the onset of peak starts at $40^{\circ} \mathrm{C}$ and the offset of peak ends in $140^{\circ} \mathrm{C}$ predicted exothermic reaction. Area under the curve was also calculated. Finally the mixture of drug and polymers showed the exothermic reaction. The peak for the polymers showed the onset of peak starts at $49^{\circ} \mathrm{C}$ and the offset of peak ends in $185^{\circ} \mathrm{C}$ and the drug melting point showed at $275^{\circ} \mathrm{C}$ as that of pure free drug. This showed the drug and polymer was more stable and exits the same melting point in the mixture of formulation. Moreover, the in-vitro release study discussed that the formulation F5 showed more percentage of drug release around $97.08 \%$, followed by F2 formulation showed $96.78 \%$, F4 formulation showed $95.33 \%$, F3 formulation showed $94.51 \%$ and F1 formulation showed $89.9 \%$ for the period of 8 hours. The F5 formulation was chosen as the best formulation based on the maximum cumulative \% drug release as shown in Figure 3. Further, the Ex-vivo study was performed for the best formulation F5 by using goat cornea were kept as membrane on the Franz diffusion cell in between donor and receptor compartment and showed the maximum percent of drug release $95.57 \%$ at the end of $7^{\text {th }}$ hour. The pharmacokinetic studies revealed that the optimized formulation F5 obeyed the Koresmeyer Peppas Reaction model $\left(\mathrm{R}^{2}\right.$ value $\left.=0.9968\right)$ and follows Non-Fickian model. Finally the 


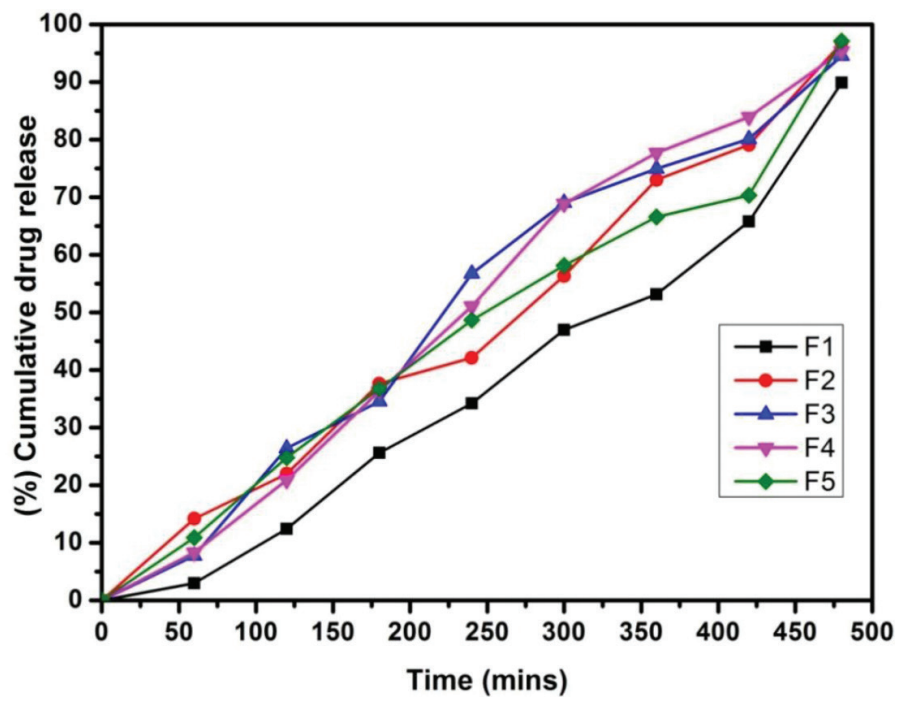

Figure 3: showed the cumulative drug release for each formulation for the period of 8 hours.
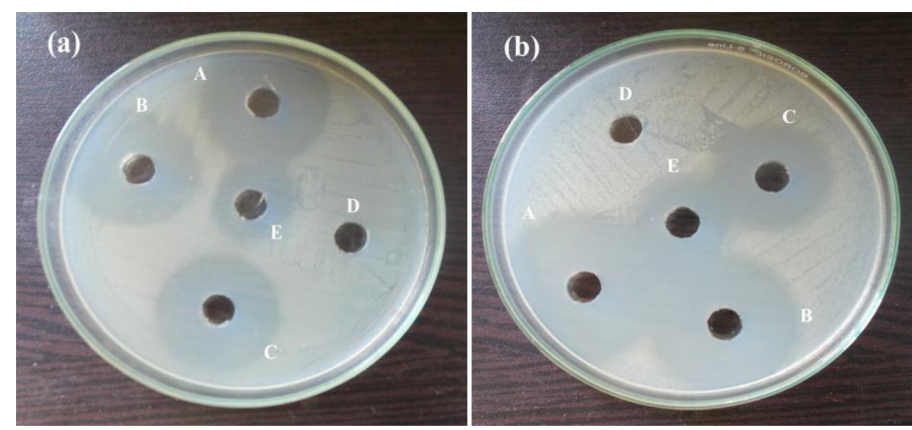

Figure 4(a): showed the zone of inhibition of formulation F5 performed with Bacillus subtilis and figure 4 (b) showed the zone of inhibition of formulation F5 performed with Escherichia coli.

The above figure clearly explains the zone of inhibition of formulation F5 at different concentrations. And it is compared with standard and negative control as shown in the Table 4.5

stability study was performed for the formulations F1-F5 as per the ICH guidelines for duration period of 0-6 months as shown in the Table 3. Moreover, the antibacterial activity of formulation F5 in-situ gel showed good zone of inhibition in the Figure 4. Both Escherichia coli and bacillus subtilis showed good similar zone of inhibition in Table 3.

\section{CONCLUSION}

The optimized formulation was prepared by simple method. The most important thing is to develop an in-situ gels which improves patient compliance with controlled release for certain period of time. Moreover, the development of in-situ gel preparation plays major role in their advantages over the conventional formulations which are available in the market. The prolonged and sustained release of particular drug showed good stability, biocompatibility and also achieves complete bioavailability. Finally, the excellent drug delivery systems could be achievable by choosing the polymers as biodegradable and soluble in water type for the preparations of in-situ gels.

\section{ACKNOWLEDGEMENT}

The Authors are very thankful to Defence Research \& Development Organization - Life Sciences Research Board (DRDO-LSRB) for their financial support.

\section{CONFLICT OF INTEREST}

The authors declare no conflict of interest.

\section{REFERENCES}

1. Araujo J, Gonazlez E, Egea MA, Garica ML, Souto EB. Nanomedicines for ocular NASIDs: safety on drug delivery. Nanomedicine. 2009;5:394-401.

2. Peppas NA, Langer R. New challenges in biomaterials. Science. 1994;263:1715-20.

3. Zhidong L, Jaiwei L, Shufang N, Hui L, Pingtian D, Weisan P. Study of an alginate/HPMC based in situ gelling ophthalmic delivery system for gatifloxacin. Int J Pharm. 2006;315(1):12-7.

4. Donnenfeld ED, Schrier A, Perry HD, Aulicino T, Gombert ME, Snyder R. Penetration of topically applied ciprofloxacin, norfloxacin, and ofloxacin into aqueous humour. Am J Ophthalmol. 1994;101(5):902-5.

5. Price FW, Whitson WE, Gonzales J, Johns S. Corneal tissue levels of topically applied ofloxacin. J Cataract Refract Surg. 1997;23(6):898-902

6. Prabhu P, Nitish KR, Koland M, Harish NM, Vijayanarayan K, Dhondge G, et al. Preparation and Evaluation of Nano-vesicles of Brimonidine Tartrate as an Ocular Drug Delivery System. J Young Pharm. 2010;2(4):356-61.

7. Shastri DH, Patel LD, Parikh RK. Studies on In situ Hydrogel: A Smart Way for Safe and Sustained Ocular Drug Delivery. J Young Pharm. 2010;2(2):116-20.

8. Patel PB, Shastri DH, Shelat PK, Shukla AK. Development and evaluation of pH triggered in-situ ophthalmic gel formulation of ofloxacin. AJPTR. 2011;1(4):430-45

9. Colthup NB. Spectra - Structure Correlations in the Infra - Red Region. J Opt Soc Am. 1950;40(6):397-400.

10. Gupta S, Samantha MK, Raichur Am. Dual - drug delivery based on in-situ gel-forming nanosuspension of forsolin to enhance anti glaucoma efficacy. AAPS Pharm Sci Tech. 2010;11(1):322-35.

11. Mohan EC, Kandukuri JM, Allenki V. Preparation and Evaluation of in-situ gels for ocular drug delivery. J Pharm Res. 2009;2(6):1089-94.

12. Mohamed MI. Optimization of Chlorphenesien Emul-gel formulation. AAPS 2004;6(3):1-7.

13. Quinones D, Ghaly ES. Formulation and characterization of nystatin gel. P R Health Sci J. 2008;27(1):61-7.

14. Abraham S, Furtado S, Bharath S, Basavaraj BV, Deveswaran R, Madhavan V. Sustained ophthalmic Delivery of Ofloxacin from An ion - activated in-situ gelling system. Pak J Pharm Sci. 2009;22(2):175-9.

15. Behera BC, Sahoo Sk, Dhala S, Barika BB, Gupta BK. Characterization of Glipizide loaded polymethacrylate microspheres prepared by An Emulsion solvent Evaporation Method. TJPR. 2008;7(1):879-85.

16. Patel P, Javia A, Sheth AK. Formulation and evaluation of sustained release chlorhexidine in situ gel for periodontitis. Die Pharmazie. 2013;4(4):465-78.

17. Sonjoy M, Manjunath KMJT, Prabhushankar GL, Geetha MS. Formulation and evaluation of an in-situ gel forming ophthalmic formulation of moxifloxacin hydrochloride. Int J Pharm Investig. 2012;2(2):78-82.

Article History: Submission Date : 18-04-2017 ; Revised Date : 31-08-2017; Acceptance Date : 29-09-2017.

Cite this article: Nagalakshmi S, Anbarasan B, Ramesh S, Thanka J, Shanmuganathan S. Formulation and Characterization of pH based Stimuli Sensitive based Hydrogels for the Treatment of Ocular Infection. J Young Pharm. 2018;10(1):32-6. 